\title{
BOUNCING BACK AND JUMPING FORWARD: SCOPING THE RESILIENCE LANDSCAPE OF INTERNATIONAL SPORTS EVENTS AND IMPLICATIONS FOR EVENTS AND FESTIVALS
}

\author{
RICHARD SHIPWAY* AND LEE MILES $†$ \\ *Department of Sport and Physical Activity, Bournemouth University, Dorset, UK \\ †Faculty of Management, Bournemouth University, Dorset, UK
}

\begin{abstract}
The purpose of this conceptual article is to critically scope the resilience landscape to help better understand how future studies on international sports events and venues could be informed by existing work in disaster management and resilience studies. The article suggests that within the differing benchmarks currently used to define and classify major international sports events, at present crises and disaster management considerations are largely ignored or underestimated. The article reviews previous research in crisis and disaster management, highlighting the potential for closer synergies between both sport and events studies and crisis and disaster management fields. It contributes new knowledge through the introduction of an international sports events (ISEs) resilience continuum to assist with better understanding resilience. The broader implications for events and festivals are highlighted. Although the interdisciplinary study of crisis, disasters, and emergency management has become increasingly sophisticated, the identification of synergies and useful concepts in relation to both sport and events studies to inform these areas is still at an early stage of development. This article adds to the limited body of knowledge on sports events resilience, and in doing so highlights potential avenues for future research in both sport and events, in terms of both theory and practice.
\end{abstract}

Key words: Resilience; Disasters; Crisis; Sports events; Continuum

Introduction

There is barely any societal sector that is not, to some extent, concerned by disasters, related resilience, and security issues (European Commission, 2015). The global sports events industry, and more broadly the events and entertainment sectors, are not exceptions. Modern society has become progressively more complex and high levels of connectivity and communication have increased public awareness, interest, and participation in international sports events. However, such interdependency

Address correspondence to Dr. Richard Shipway, Senior Principal Academic, Department of Sport and Physical Activity, Bournemouth University, Dorset House, Fern Barrow, Poole, Dorset, BH12 5BB UK. Tel: +44 1202 965692; E-mail: rshipway@bournemouth.ac.uk 
is not without costs. Interdependency also increases vulnerability to international crisis and disasters that are becoming ever more regular due to, for example, climatic change, globalization, and international political trends (Miles, 2016a). Interest in crises and disasters among sports events communities is directly and indirectly fueling ever greater demands for increasing resilience.

At the same time, on the global stage, the pursuit of a more comprehensive approach to crisis and disaster management has come into focus in recent years. The United Nations Sendai Framework for Disaster Risk Reduction 2015-2030, that sets out the evolving global agenda for international crisis and disaster management, places concepts of "resilience" center stage. Sendai also envisages "an inclusive and all-of-society disaster risk management that strengthens synergies across groups” (United Nations, 2014, p. 23). It also fully recognizes that "nonstate stakeholders" such as business, professional associations, and the private sector should be more integrated into international disaster management to enhance resilience (United Nations, 2014, p. 23).

As such, there seems to be a demonstrable link between the interests and agendas of the management of international sports events (ISEs) and crisis and disaster management. Nevertheless, even though sport represents a significant (nonstate) sector, it is noteworthy that international frameworks such as Sendai do not make specific reference to the sports industry. This is in contrast to some other sector areas in the leisure domain such as tourism (United Nations, 2014), so there may therefore be issues of visibility here. Regardless of this, there remains considerable work required to investigate the nature, complexity, and connectivity of the practical links between ISEs and disaster management. Indeed, authors of resilience have highlighted that although resilience "is often presented as an approach that has the potential to bridge different fields," these fields still often work in isolation (De Milliano \& Jurriens, 2017, p. 260).

This increased (public) awareness of vulnerability and the need for greater resilience, merged with the growing global profile of ISEs, now makes mitigation and prevention not just socially and economically acceptable, but also an imperative (see Shipway, 2018). As such, this article facilitates movements towards a broader interdisciplinary research agenda that incorporates sports events, and has broader, far reaching implications for critical event studies.

\section{Defining Resilience}

When reviewing existing literature sources and theoretical concepts, an appropriate starting point is to clarify the concept of resilience, its origins, and development in a range of disciplinary studies, and its relevance within both sport and events contexts. The origins of the English word resilience can be traced back to the Latin word resilio, literally translated meaning to jump back (Klein, Nicholls, \& Thomalla, 2003). Thus, resilience generally refers to the capability of a system to recover after undergoing significant disturbance. Originating from ecology studies, resilience was initially viewed as maintaining stability and defined as the ability of a system to return to an equilibrium state after disturbance (Holling, 1973). Resilience theory has evolved to recognize the inherent uncertainty in predicting the complex and dynamic nature of how individuals, organizations, and society respond to change (Gallopín, 2006). As such, resilience is both a multifaceted and multidimensional concept (Ponomarov \& Holcomb, 2009), relating to a variety of topics ranging from physical material properties to supply chain management, resulting in a diverse literature base.

Growing "multifaceted" awareness of resilience has also led to it becoming an increasingly central organizing metaphor (Alexander, 2013). According to Chandler and Coaffee (2017), resilience is often defined "as a capacity to prepare for, to respond to, or to bounce back from problems or perturbations and disturbances” (p. 4). Moreover, resilience can particularly shape responsiveness and even act as a major catalyst for change (Miles, 2016b).

Fundamentally, the concept of resilience is closely related with the ability of an element or system to return to a stable state after a disruption (Gunderson, 2000). Organizational systems are subjected to both internal and external risks, and therefore they have an unpredictable and uncertain future (Burnard \& Bhamra, 2011). Scholars highlight that one issue with risk management is that risk is hypothetical until it turns into a crisis 
or disaster (Alexander, 2003). As such, it is only in hindsight that crises and disasters are viewed as events that should have been planned and prepared for (Miles, 2016b; Ritchie, 2009). According to Taylor and Toohey (2015), risk is "the possibility of loss resulting from a threat, security incident, or natural disaster” (p. 389). In relation to operational risk and safety management discussed in the domain of sports event studies, risk management involves the consideration of the likelihood of a threat endangering an asset, function, or individual. This broad categorization can range from counterterrorism intelligence or command, control, and communication through to event security management plans and security. This article suggests that the concept of resilience is far broader than the narrower and more focused assessments of the standardized risk management practices previously explored in both sport and event studies.

The resilience concept overlaps to a large degree with the concepts of vulnerability and adaptive capacity (Gallopin, 2006). Resilience, with its origins in systems ecology, has a more systemsoriented approach, whereas the concepts of vulnerability and adaptive capacity focus more on the actors and their response to change (Adger, 2006). Specifically, vulnerability is the susceptibility of a system to disturbances and is determined by exposure and sensitivity to perturbations and the capacity to adapt (Gallopin, 2006; Nelson, Adger, \& Brown, 2007). Although a deeper critique on both vulnerability and adaptive capacity is beyond the scope of this article, it is logical to assume that the more vulnerable a sports event or venue is, the more extreme the impact of a given shock will be. Likewise, and also applicable to events more generally, if that event or venue also has little adaptive capacity, then that shock is more likely to generate a sustained, permanent change of state. Hence, the link to resilience: if a sports event or venue is vulnerable and has little adaptive capacity, then a shock is more likely to shift it from one "state" to another (Biggs, Hall, \& Stoeckl, 2012).

\section{Crisis and Disaster Management in Sports Events}

Although various studies are evident in the tourism domain (Faulkner, 2001; Laws \& Prideaux, 2006; Mair, Ritchie, \& Walters, 2014; Ritchie,
2004, 2009), and there is no desire to replicate or further dissect many of these, an initial review of literature on crisis and disaster management in sport indicates a significant paucity of studies. More specifically in the field of sport management studies, crisis and emergency dimensions are not mentioned with any depth or with reference to the existing crisis and disaster management literature (see Hall, 2016). Those studies of resilience in sport to date are primarily restricted to either community sports clubs' responses to natural disasters (Filo, Cuskelly, \& Wicker, 2015), the relationship between team identification and social well-being in times of adversity (Inoue, Funk, Wann, Yoshida, \& Nakazawa, 2015), disaster relief activities implemented by sports organizations and athletes (Inoue \& Havard, 2015), or the psychological resilience of the individual athlete or team, from a performance perspective (Galli \& Gonzalez, 2015). These latter studies are interested in resilience from the perspective of humans (athletes and fans) who have been exposed to challenging circumstances and their ability to respond positively and overcome personal adversity.

Despite these contributions and the wider body of tourism-specific work, in the domain of sports events studies the field is clearly at an early and descriptive stage with considerable work to be undertaken on shaping research agendas and future directions (Shipway, 2018). As such, in the context of ISEs it is important to identify gaps in knowledge and contribute to understanding future research directions, most notably with respect to developing resilience. In doing so, this article also highlights implications that are equally applicable for events and festivals.

Therefore, this article now undertakes the primary task of assessing the differing benchmarks used to define and classify international sports events and suggests that, at present, crises and disaster management considerations are largely ignored or underestimated. This is despite such classifications having major implications and connotations in terms of understanding resilience. Second, the article evaluates how relevant crises and disaster management approaches can provide value added to the broader literature on event studies. Third, it then highlights where there are appropriate synergies for future development. On this basis we 
then advocate further studies to help improve and provide better understanding on why and how ISEs practice resilience in the future, and become more robust at handling crises and disasters.

\section{Reevaluating Definitions and Classifications of ISEs: A Resilience Perspective}

In the domain of sports event-related studies there remains a degree of ambiguity when classifying sports events, arenas, stadiums, and venues. Many of the current benchmarks that define ISEs, irrespective of scale, seniority, and/or status, are largely based around perceptions of importance, internationalization, complexity, and size (Getz, 2008; Gratton \& Taylor, 2000; Hiller, 2000; Horne, 2007; Müller, 2015; Roche, 2000). Previous studies surrounding sport, leisure, tourism, and event management have adopted a range of these criteria in attempts to define ISEs. However, and importantly, those discussions have not incorporated any significant critical dialogue on the impact of crises and disasters. This is surprising given that such large sports events are using criteria that are similar to those used to define critical infrastructure (CIs) in the crisis and disaster management literatures (Boin \& McConnell, 2007). This implies notable risk factors that may come to fore at times of external shocks and even result in discernible loss of life, sizable casualties, and substantial infrastructural damage. CI is a term used to describe government assets that are crucial for the effective functioning of a society and economy that include public health, agriculture, shelter, heating, transportation systems, water supply, electricity generation, telecommunications, and security services (Coaffee \& Clarke, 2016).

This poses questions as to why notions of crisis and disaster management have not featured prominently when classifying and defining ISEs. The delivery of successful ISEs is partly reliant upon having the appropriate capacity of suitable and effective international sports venues (ISVs). Solely for the purpose of this article, an ISV is defined as a "structure, building or place in which a sporting competition is held” (Shipway \& Fyall, 2012, p. 6). They represent physical structures, buildings, or places that host large groups of participants or spectators and include arenas, stadiums, convention centers, racetracks, and amphitheaters (Masteralexis, Barr, \& Hums, 2012). Within this relatively broad ISV definition used explicitly here for the context of exploring resilience, there is notable variation. For example, there are differences between international sports arenas (ISAsindoor facilities that host sports and entertainment events) and international sports stadium (ISS-outdoor or domed facilities). ISVs may also be multifunctional, housing multiple teams and coexisting multisports events, and may incorporate adjacent practice facilities. In the context of this resiliencefocused article and to simplify matters, the overarching terms of ISEs and ISVs will be used, which also incorporate stadiums and arenas.

A brief overview of the present conceptualizing of ISEs and their component parts is now considered. The aim is to identify existing and potential research gaps in sports event-related research, and opportunities for future studies that explicitly explore resilience. Although the context of the article is sports events, there is a recognition of parallels and synergies across the spectrum of critical event studies including urban recreation gatherings, tourism destinations, entertainment venues, and festivals.

\section{Bouncing Back: ISEs and the Implications for Resilience}

In the field of ISEs, while the rationale for bidding, hosting, and evaluating impacts is frequently economic (Li \& Jago, 2012), the desire to consider sports events has been partly driven by output dependencies. These have included research on potential changes in sports participation, assessing impacts upon social dimensions of host communities, investigating largely material (economic) benefits, identifying linkages to environmental initiatives, and identifying opportunities for enhancing tourism (Chien, Ritchie, Shipway, \& Henderson, 2012; Deery, Jago, \& Fredline, 2012). However, Shipway and Fyall (2012) also suggested that it is largely problematic when defining the different types and characteristics of ISEs, given they also vary widely in scope, scale, and structure. When examining the larger sports events many scholars (e.g., Hiller, 2000; Horne, 2007; Roche, 1994) prefer the term "mega-event." Yet there remains a lack of precise 
terminology, and there are clear and apparent overlaps with discussions within leisure studies.

There are also debates in the sport and events literature about which events could be classed as "mega-events," but it is striking how little notions of resilience have featured in such debates to date. In the sports event literature, both Masterman (2014) and Chappelet and Parent (2015) also questioned what defines a mega-event and the gradients used to differentiate them from what constitutes a "minor event." Similarly, in the events studies context seminal authors such as Getz (1997) and Jago and Shaw (1998) also defined events differently. More recently within the leisure studies literature Müller (2015) argued that the distinction between a large event and a mega-event is essentially one of size. He classified large events into three size classes: major events, mega-events and giga-events. Müller's definition proposed that mega-events are occasions of a fixed duration that attract a large number of visitors, have a large mediated reach, involve large costs, and have significant impacts on populations and the built environment.

Chappelet and Parent (2015) suggested that sports events is a generic term that covers a range of events from local sports competitions to the Olympic Games. They acknowledged that they can be categorized by various parameters including size, spatial and temporal characteristics, sport-specific aspects, renown, and financial objectives. In doing so, they initially identified a simplistic typology of sports events based on media coverage as (1) (very) big XL and L events; (2) medium-sized (M) events; and (3) (very) small (S and XS) events. In a more detailed analysis Chappelet and Parent then advocated a more advanced typology with a clearer focus on the nature of the event rather than size. Their proposed typology is based on three dimensions; (1) for profit or nonprofit, (2) incorporating either monosport or multisports, and (3) whether the events were one-off or recurring in nature. In terms of developing resilience, the mono- or multisport dimension has major implications given the number and diverse nature of stadiums and/or venues required to stage the event. From a resilience perspective, it is logical to first suggest that multisport events will pose more challenges, and second, it is perhaps also logical to assume that the majority of monosport events will use fewer stadiums and/or venues than multisport Games. This will also have notable implications for planning and developing greater levels of resilience. Additionally, given that long standing recurring events are often hosted in the same host city, this might also indicate greater levels of experience and knowledge management than less frequent emerging, one-off major or megainternational sports events (see Shipway, 2018).

As alluded to above, despite the globalized nature of sports events and debates about the size components of more recent large sports events, none of these classifications pay attention to criteria relating to resilience. Given that the characteristics of sports events will vary across their size and scope, it is suggested that this will present different challenges in terms of managing crises and disasters. This seems pertinent given that there is a usual assumption that the bigger the sporting event, and therefore size of event participation and audiences, the larger and more complex are the array of associated hazards and risks. In his classification of major and mega-sports events Müller (2015) pointed to the complexity and high input costs, which includes security that are required to deliver mega-events. Similarly, Jennings (2012) identified that the complexity of events, with parallel projects across different sectors including security, leads to pressure for increased coordination. Yet these are not very well defined, and this is a limitation to the classifications proposed by Müller. In addition, this article partially responds to Müller's request for future studies that help to build a more complete and systematic exploration of the main dimensions of large events, and what makes an event a megaevent. There are notable risk management and resilience implications of such categorizations, not least in examining issues relating to sports event resilience and crisis and situational awareness.

Towards a Critical Turn:

\section{ISEs’ Resilience-Specific Classifications}

The various classifications and typologies highlighted above serve to further illustrate the diversity of sports events, and subsequently the challenges faced by both major and mega-sports events when trying to develop greater levels of resilience. To facilitate future discussions and potential research agendas on sport-specific resilience, this article 
now considers the revised introduction of a preliminary working subdivision of ISEs into three broad categories. These three working categories are "Mega-ISEs," "Large-Scale Major ISEs," and "Smaller-Scale Major ISEs." It is suggested these categories better cope with the recognition that ISEs are multidimensional. They also partially address the limitations of Müller's (2015) definition of what makes an event a mega-event, in terms of both definitions and size.

\section{Mega-ISEs and Resilience}

The first resilience specific proposed classification of "Mega-ISEs" equates to global, often premier, usually held every 4 years. These would include international spectator events such as Olympic Games, FIFA World Cup, UEFA European Football Championships, or equivalent. Association Football tournaments are clearly monosport events. Whether mega-events are considered to be "mega" due to being "discontinuous," out of the ordinary, international, large in scale, or having the ability to transmit media messages to billions of people (Roberts, 2004; Roche, 2000), there remains minimal, if any reference to the extent of their resilience. More generally, there is recognition that this "mega" characteristic equates to a highly complex sporting event of international/world-class significance that normally involve huge international crowds, organized around both single and multiple sports and diverse venues (ISV's) over a notable period of time (weeks).

More specifically, in terms of resilience; first, they will have multifaceted implications due to their complexity and thus affect resilience in spatial (space/scale) terms. As such, more complicated crisis planning may be necessary because the types and forms of hazards may be more numerous, and vulnerability greater. The involvement of a wider array of stakeholders may be necessary in order to handle the complex menu of differing events, venues, and sport-specific requirements that might even include coverage over multiple cities or countries. Second, they have mega-international significance in terms of global reach, where the world (media coverage) is watching not just the sport but also their levels of resilience. Crisis managers are keen to avoid incidents happening while the international media and public are watching. This will require communication with national and not just international audiences and publics. Third, there are implications for resilience in temporal terms (time) in that they are usually held over an extended period of weeks rather than days. Therefore, they require more complicated and longer lasting crisis and disaster management arrangements to ensure greater resilience while the sporting event is being planned and hosted. As such, it is suggested that these aspects should be taken into consideration when defining and classifying whether a sports events is termed as "mega."

\section{Large-Scale Major ISEs and Resilience}

The second proposed resilience specific classification relates to "Large-Scale Major ISEs" such as major, usually annual, single sport spectator and/ or competitor events. For example, comparable sports events in the UK context might include the Grand National Horse Race in Liverpool, the Silverstone F1 Grand Prix event in Northamptonshire, Wimbledon Tennis tournament, or equivalent. To further illustrate such events, additional alternative equivalents in an Australian context might include the F1 Grand Prix, Australian Open Tennis Championship, or the Melbourne Cup Horse Race, all which are hosted in Melbourne. North American parallel events might include the Kentucky Derby, the Indianapolis 500 automobile race at Speedway, Indiana, or the US Open Tennis Championship at Flushing Meadows, New York. Some of these are also what both Masterman (2014) and Chappelet and Parent (2015) referred to as "recurring" ISEs such as the four major tennis "Grand Slams," the Football Association (FA) Cup Final, and Formula One motor racing Grand Prix festivals.

In contrast and in relation to resilience, these large-scale major ISEs are characterized by first, their annual scale, in excess of 50,000-100,000 visitors per day, and their international significance. Yet, there is relatively reduced complexity in that they usually take place at one or few venues. In this way although the demands for resilience may be the same, the fact that fewer (often similar) venues are being used should reduce types and forms of hazards and vulnerability to crisis and disaster. Second, they are characterized by their status as 
national events that nonetheless have significant international reach in terms of attracting global competitors, spectators, workers, volunteers, and media coverage. For the most part, they will attract international attention and assessments on their safety and resilience. Third, in temporal time terms, they are characterized by the fact they are usually, but not always, held over a number of days, or regularly throughout the calendar of the sporting year. Generally, they are unlikely to last for weeks or of the time duration expected of so called "megaevents." Thus, while still complicated, they may represent less of challenge in relation to developing resilience and maintaining vigilance.

\section{Smaller-Scale Major ISEs and Resilience}

In terms of scoping the resilience landscape, a third tentatively proposed classification is "Smaller-Scale Major ISEs." This categorizes sports events that first, attract a smaller scale in terms number of spectators (5,000-50,000 visitors per day). However, while still retaining a high level of competition they nevertheless have less complexity in taking place at single, if notable, flagship international sports venues (ISVs). Examples might include national athletics championships, city marathon events, or frequently-occurring Premier League Football or Rugby events, to name but a few examples. It is recognized attendances, for example in the Association Football context, that will most likely exceed our indicated 50,000 upper attendance level. A second characteristic is their more limited significance in terms of international reach and media coverage. The third characteristic is their limited time duration, being that they are normally held on a single day, over an extended period of days, or regularly throughout the sporting year. In terms of resilience it is proposed that they are much less of a commitment in terms of resourcing and management. They will also have a lower propensity to involve international stakeholders and audiences. As such, it is suggested that there are fewer considerations to be factored into crisis management planning, such as communication and information systems planning.

These three proposed resilience-specific working definitions of sports events are also complemented by the way that Jago and Shaw (1998) differentiated in terms of size and scale. They propose that changing host location to ensure global reach and status is a key characteristic of the "mega" classification. As both Shipway and Fyall (2012) and Chappelet and Parent (2015) indicated, "mega"-events may be summer and/or winter events such as the FIFA World Cups and other international championships. They are all biddable by host countries and destinations, and tend to be "one-timed" staged events. From a resilience perspective, this additional dimension of changing host location, often due to the increasingly competitive biddings agenda of many host cities and nations, represents a notable proposition that has major implications for the way we think about the resilience of such events in terms of crisis and disaster management. For example, variations in sites of mega-events, such as Olympic Games or FIFA Football World Cups, also leads to much greater complexity in gauging risk to crisis and disasters that are differentiated across the world (Shipway, 2018).

In terms of vulnerability to natural disasters, differing regions and host countries are subject to variances in types, forms, and frequency of natural hazards, such as earthquakes, volcanic eruptions, cyclones, and/or tsunamis (see Miles, Gordon, \& Bang, 2017). Additionally, as the Rio 2016 Olympic and Paralympic Games highlighted with the zika virus, there are differing vulnerabilities to health hazards and even communicable diseases (Shipway, 2018; Walters, Shipway, Miles, \& Aldrigui, 2017). Moreover, in the developing world, man-made threats and risks such as crime rates, kidnapping, insurgencies, terrorism, or conflict may be more notable. The resilience challenges of providing integrated planning and procedures to handle such natural hazards and man-made threats while such ISEs are taking place in developing world countries are considerable. This places new pressures on the capacities of host nations and societies. Initiatives encouraging the globalization of the sports events industry as well as the contemporary policies and strategies of world sports governing bodies and international federations have often sought to extend the reach of their respective events to audiences not reached before. This often involves host cities and nations with little or no prior experience gaining the right and contracts to host such events. This leads to differing degrees of resilience for 
every individual mega-event, such as the Olympics or the FIFA World Cup. In these circumstances no two mega-events will ever be the same, not just in space but over time.

\section{Jumping Forward: An ISE Resilience Continuum}

Given the differing degrees of resilience that are proposed above, where no two mega-events will ever be the same, this article proposes the development of an "International Sports Events Resilience Continuum," to interpret resilience aspects of Mega-ISEs over time. Given that there is now much greater diversity in host nations across the world seeking to, and hosting Mega-ISEs, then it is likely that there will also be higher levels of variations in both risk and resilience levels over time. This would even apply for similar types of Mega-ISE due to changes in the host cities and nations. Similarly, learning from past experiences may be complicated and uneven around the globe, and lessened by potential challenges to effectively transfer knowledge and best practice in crisis and disaster management from one region or continent or nation to another. Notions of safety and security not only features in today's debates on how host sites for major tournaments are chosen, but also in the prevailing attitudes of spectators on where to travel and when to attend (Qi, Gibson, \& Zhang, 2009; Walters et al., 2017).

In general, the time line continuum of resilience for particular types of ISEs may not be as linear or ever improving as first appears (see Fig. 1). The implicit assumption that the more a particular type of Mega-ISE is held over time the more experienced the organizers will become at ensuring better resilience may simply not be accurate. It may actually be dramatically different over time given the variations in risk and resilience from one Mega-ISE to another, especially if the host location also changes. Conversely for Smaller-Scale Major ISEs it may be the case that a more linear, consistent, and even improving levels of resilience can be expected, if an ISE resilience continuum is applied at event, venue, and organizational levels. This is logical given they are often hosted in the same

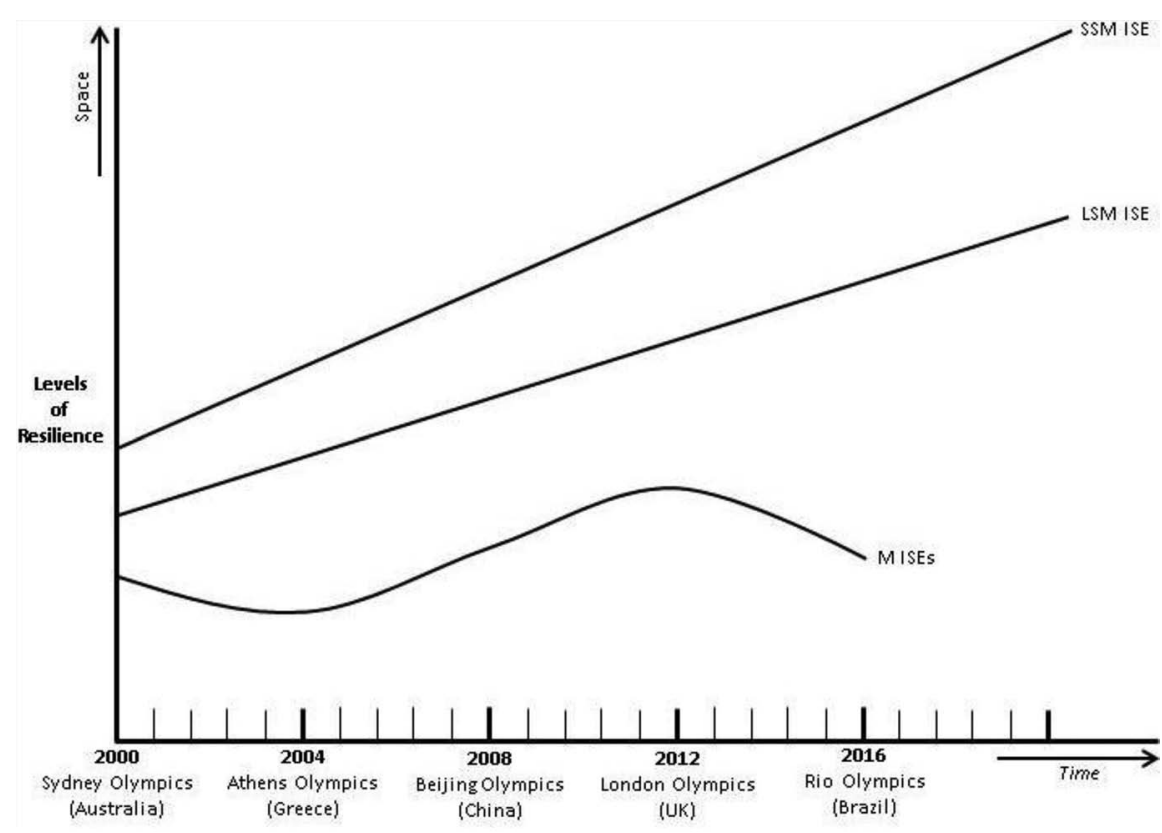

Figure 1. International sports events (ISEs) resilience continuum. SSM ISE: Single sport, single venue, same place, single/small number of days' duration. LSM ISE: Flagship national sports events, single/few venues held over number of days. M ISE: Multiple sports, international reach, multiple venues with a changing host nation, held over number of weeks, not annual. Source: Authors. 
country, mostly at, or shared among a small number of similar venues, and occur annually each year. As such it is highly probable that lessons in crisis and disaster management can be identified, shared, and learned more easily, assessed more readily, and possibly improved on year on year. In the case of Large-Scale Major ISEs the likelihood is that levels of resilience may lie somewhere in between. They might be more linear and progressive but less steep or stable in terms of learning.

It may be useful for future studies on sports events to factor greater attention to, and more sophisticated appreciations of, resilience when deciding which sports events or tournaments are perceived as "successful" or "effective" by a wide range of stakeholders including international federations, governments, and global media commentators. By incorporating notions of an "ISE Resilience Continuum" this helps us to explore a key assumption: namely Mega-ISEs may actually have lower levels of event or venue resilience over space and time than Smaller-Scale Major ISEs. This is given their complexity and limitations in the ability to apply lessons learned over time. Indeed, this may be counter intuitive given that Mega-ISEs such as the Olympic Games often have state of the art new venues where the best resilience safeguards and friendly technology may be in place. As such, it is suggested that future research is required to further explore what we have termed as "sports event and venue resilience."

In addition, future studies are advisable that move towards developing a resilience continuum for a diverse range of events and festivals, be they art, cultural, or music based. These will vary in both size and scale, and also potentially have significant variations in terms of resilience. To elaborate further, in the broader context of events and festivals, it is perhaps logical to assume a resilience continuum would also exist, based on differing size and scale. For example, when exploring differing resilience between music festivals in the UK context this might include a resilience analysis of differing events on an "Events and Festivals Resilience Continuum.” An example might include (1) Glastonbury or the Isle of Wight festivals, both with a globally recognized profile, highly acclaimed reputations, complex infrastructure, and hosted over an extended period of days; (2) annual domestic weekend festival events, of a slightly smaller size but still regarded as internationally significant, such as the Bestival or Wireless Festivals; or (3) singular 1-day, primarily evening concerts or gigs at music venues such as Shepherd's Bush Empire or Brixton Academy in London. These are similar in size and scale to the Bataclan theatre in Paris, France, site of the November 2015 terrorist atrocities.

\section{Conclusions}

The aim of this article is to make a contribution to current thinking on ISEs and resilience, and in doing so to also stimulate new discussions and debates among scholars in the broader domain of critical event studies including festivals, urban recreation gatherings, tourism, and entertainment venues. By harnessing the potential for closer synergies between the sports events and crisis and disaster management fields, there are notable possibilities to substantially move forward our understanding of the complexities of sports events and venues, both in terms of theory and practice. Moving forward, there is a need for additional work that scopes the resilience landscape in terms of future research agendas that may help us to further understand how studies on ISEs and broader events and festivals of contrasting size and scale could be informed by disaster management and resilience studies.

The previously highlighted research on disaster management and risk management within a leisure context, primarily located within tourism studies, has adopted a more "top-down" tradition. These focused on organizations, planning, and cooperation, and addressed issues relating to mitigation, preparation, responding, and recovery (Mair et al., 2014; Ritchie, 2009). The purpose of this scoping article is to critique ISEs through the lens of resilience. As such, it is proposed that in both the sport and events context this is potentially more feasible with future studies adopting a more "bottom-up" ethos, with the focus on (1) sport and leisure organizations/events; (2) societal/community aspects of sport and events; and (3), the individual participant or event/festival attendee.

As such, three main areas of future research focus within both sport and event contexts are suggested. These are (1) a capacity focus; (2) a movement away from top-down to bottom-up approaches; and 
(3) future studies that adopt a process orientation, whereby both sport and events can move from building to developing better resilience. Fundamentally, when scoping resilience landscapes, the foundational literature within crisis and disaster management studies highlight that "context is everything" (Haldrup \& Rosen, 2013, p. 137), and as such the theoretical exploration suggested has been embedded within the context of sports events. This perspective also supports the previously advocated views of Horne (2007), who highlighted the need to critically explore the assumptions, beliefs, and misrepresentations that are often repressed about sports mega-events when exploring the notion of "knowns" and "unknown knowns."

In terms of potential limitations, it is explicitly acknowledged that the resilience classifications provided herein are sport-specific "working” definitions. As such, far greater potential exists for broader investigation across a diverse range of event and festival spaces where large public gatherings are a frequent occurrence. The logical argument for expansion beyond the context of sports events to event and entertainment contexts more generally is perhaps even more pressing given the more recent terror attacks have occurred within leisure, drinking, and general socializing environments or spaces. The London 2017 bombings, music events like the 2015 Eagles of Death Metal concert at the Bataclan theatre Paris, or the 2017 Ariana Grande concert at the MEN Arena in Manchester are just three selected examples. To support this perspective, given this article advocates future studies that explore opportunities and avenues within the broader events context this should include studies at demonstrations/ marches, political rallies, music concerts, and religious gatherings. These future studies should also include diversifying to explore specific leisure-based event locations such as concert halls, restaurants/ pubs and drinking establishments, airports/railway stations, places of worship, shopping centers/malls, streets and parks, or theaters.

The theoretical contribution of this article is the development of an "ISEs resilience continuum" that extends research on resilience within a sports-specific context. As highlighted previously, this is also one that has major implications for broader events and festivals that incorporate mass gatherings. Further to the theoretical contribution, this research has practical implications for decision makers and event and venue managers in developing suitable resilience strategies in order to be prepared for uncertain events (Alexander, 2013). This article argues that the concept of sport and venue resilience is related to ecological resilience, exploring the ability of sports events and venues to cope with external stresses and disturbances. This is while also maintaining both their functional characteristics and their well established and clearly defined sport and event identities (Shipway \& Fyall, 2012).

Not only is there a pressing interdisciplinary research agenda but there are also notable practical implications that should give ISEs and venues a better "sporting chance" of handling crisis and disasters in the future. To address Horne's (2007) reservations, the logic, assumptions, and perspectives presented in this scoping article are taken from previous research in the context of crisis and disaster management that has yet to be tested in either the sports events context or broader events space. As such, to move this research agenda forward, there is a clear need to empirically engage with this topic "in the field." This is a current limitation of this article. In doing so, this will add rigor and relevance to the "ISE resilience continuum" proposed in Figure 1. One thing is certain - neither the schedules of future sports events and tournaments, nor the likelihood of future threats and hazards will wait for scholars of both sport or event studies and crisis and disaster management to open up a more effective dialogue.

\section{References}

Adger, W. N. (2006). Vulnerability. Global Environmental Change, 16(3), 268-281.

Alexander, D. (2003). Towards the development of standards in emergency management training and education. Disaster Prevention and Management: An International Journal, 12(2), 113-123.

Alexander, D. (2013). Resilience and disaster risk reduction: An etymological journey. Natural Hazards and Earth Systems Sciences Discussions, 1, 1257-1284.

Biggs, D., Hall, C. M., \& Stoeckl, N. (2012). The resilience of formal and informal tourism enterprises to disasters: Reef tourism in Phuket, Thailand. Journal of Sustainable Tourism, 20(5), 645-665.

Boin, A., \& McConnell, A. (2007). Preparing for critical infrastructure breakdowns: The limits of crisis management and the need for resilience. Journal of Contingencies and Crisis Management, 15(1), 50-59. 
Burnard, K., \& Bhamra, R. (2011). Organisational resilience: Development of a conceptual framework for organisational responses. International Journal of Production Research, 49(18), 5581-5599.

Chandler, D., \& Coaffee, J. (2017). Introduction: Contested paradigms of international resilience. In D. Chandler \& J. Coaffee (Eds.), The Routledge handbook of international resilience (pp. 3-9), London, UK: Routledge.

Chappelet, J. L., \& Parent, M. (2015). The (wide) world of sports events. In M. Parent \& J. L. Chappelet (Eds.), The Routledge handbook of sports event management (pp. 1-17), London, UK: Routledge.

Chien, P. M., Ritchie, B. W., Shipway, R., \& Henderson, H. (2012). I am having a dilemma: Factors affecting resident support of event development in the community. Journal of Travel Research, 51(4), 451-463.

Coaffee, J., \& Clarke, J. (2016). Critical infrastructure lifelines and the politics of anthropocentric resilience. Resilience, 5(3), 161-181.

Deery, M., Jago, L., \& Fredline, L. (2012). Rethinking social impacts of tourism research: A new research agenda. Tourism Management, 33(1), 64-73.

De Milliano, C., \& Jurriens, J. (2017). A different cup of tea. In D. Chandler \& J. Coaffee (Eds.), The Routledge handbook of international resilience (pp. 260-261). London, UK: Routledge.

European Commission. (2015). Secure societies-Protecting freedom and security of Europe and its citizens. Retrieved from https://ec.europa.eu/programmes/horizon2020/en/ h2020-section/secure-societies-\%E2\%80\%93-protectingfreedom-and-security-europe-and-its-citizens

Faulkner, B. (2001). Towards a framework for tourism disaster management. Tourism Management, 22, 135-147.

Filo, K., Cuskelly, G., \& Wicker, P. (2015). Resource utilisation and power relations of community sports clubs in the aftermath of natural disasters. Sport Management Review, 18, 555-569.

Galli, N., \& Gonzalez, S. P. (2015). Psychological resilience in sport: A review of the literature and implications for research and practice. International Journal of Sport and Exercise Psychology, 13(3), 243-257.

Gallopín, G. C. (2006). Linkages between vulnerability, resilience, and adaptive capacity. Global Environmental Change, 16(3), 293-303.

Getz, D. (1997). Event management and tourism. New York, NY: Cognizant Communication Corp.

Getz, D. (2008). Event tourism: Definition, evolution, and research. Tourism Management, 29, 403-428.

Gratton, C., \& Taylor, P. (2000). Economics of sport and recreation. London, UK: E \& FN Spon.

Gunderson, L. H. (2000). Ecological resilience-in theory and application. Annual Review of Ecology and Systematics, 31(1), 425-439.

Haldrup, S. V., \& Rosen, F. (2013). Developing resilience: A retreat from grand planning. Resilience, 1(2), 130-145.

Hall, S. (2016). Crisis management. In T. Byers (Ed.), Contemporary issues in sports management (pp. 391-403). London, UK: SAGE.
Hiller, H. (2000). Toward an urban sociology of mega events. Research in Urban Sociology, 5, 181-205.

Holling, C. S. (1973). Resilience and stability of ecological systems. Annual Review of Ecology and Systematics, $4(1), 1-23$

Horne, J. (2007). The four "knowns” of sports mega-events. Leisure Studies, 26(1), 81-96.

Inoue, Y., Funk, D. C., Wann, D. L., Yoshida, M., \& Nakazawa, M. (2015). Team identification and postdisaster social well-being: The mediating role of social support. Group Dynamics: Theory, Research, and Practice, 19(1), 31-44.

Inoue, Y., \& Havard, C. T. (2015). Sport and disaster relief: A content analysis. Disaster Prevention and Management, 24(3), 355-368.

Jago, L., \& Shaw, R. (1998). Special events: A conceptual and differential framework. Festival Management \& Event Tourism, 5(1/2), 21-32.

Jennings, W. (2012) Olympic risks. Basingstoke, UK: Palgrave Macmillan.

Klein, R. J. T., Nicholls, R. J., \& Thomalla, F. (2003). Resilience to natural hazards: How useful is this concept? Global Environmental Change Part B: Environmental Hazards, 5(1-2), 35-45.

Laws, E., \& Prideaux, B. (Eds.). (2006). Tourism crises: Management responses and theoretical insight. London, UK: Routledge.

Li, S., \& Jago, L. (2012). Evaluating economic impacts of international sports events. In R. Shipway \& A. Fyall (Eds.), International sports events: Impacts, experiences and identities (pp. 13-26). London, UK: Routledge.

Mair, J., Ritchie, B. W., \& Walters, G. (2014). Towards a research agenda for post-disaster and post-crisis recovery strategies for tourist destinations: A narrative review. Current Issues in Tourism, 19(1), 1-26.

Masteralexis, L. P., Barr, C. A., \& Hums, M. A. (2012). Principles and practice of sport management: Fourth edition. London, UK: Jones and Bartlett Learning.

Masterman, G. (2014). Strategic sports event management (3rd ed.). London, UK: Routledge.

Miles, L. (2016a). The five “'C's”: Synergies in international disaster management and public health and a place for entrepreneurial resilience? Perspectives in Public Health, 136(6), 323-325.

Miles, L. (2016b). Entrepreneurial resilience. Crisis Management Journal, 11(4), 52-54.

Miles, L., Gordon, R., \& Bang, H. (2017). Blaming active volcanoes or active volcanic blame? Volcanic crisis communication and blame management in the Cameroon. In C. J. Fearnley, D. K. Bird, G. K. Haynes, W. J. McGuire, \& G. Jolly (Eds.), Observing the volcanic world: Volcanic crisis communication (pp. 1-15). New York, NY: Springer.

Müller, M. (2015). What makes an event a mega-event? Definitions and sizes. Leisure Studies, 34(6), 627-642.

Nelson, D. R., Adger, W. N., \& Brown, K. (2007). Adaptation to environmental change: Contributions of a 
resilience framework. Annual Review of Environment and Resources, 32(1), 395-419.

Ponomarov, S. Y., \& Holcomb, M. C. (2009). Understanding the concept of supply chain resilience. The International Journal of Logistics Management, 20(1), 124-143.

Qi, C., Gibson, H. J., \& Zhang, J. J. (2009). Perceptions of risk and travel intentions: The case of China and the Beijing Olympic Games. Journal of Sport and Tourism, 14(1), 43-67.

Ritchie, B. W. (2004). Chaos, crises, and disasters: A strategic approach to crisis management in the tourism industry. Tourism Management, 25, 669-683.

Ritchie, B. W. (2009). Crisis and disaster management for tourism. Clevedon, UK: Channel View Publications.

Roberts, K. (2004). The leisure industries. London, UK: Palgrave.

Roche, M. (1994). Mega-events and urban policy. Annals of Tourism Research, 21, 1-19.
Roche, M. (2000). Mega-events and modernity. London, UK: Routledge.

Shipway, R. (2018). Building resilience and managing crises and disasters in sport tourism. Journal of Sport \& Tourism, 22(3), 265-270.

Shipway, R., \& Fyall, A. (Eds). (2012). International sports events: Impacts, experiences and identities. London, UK: Routledge.

Taylor, T., \& Toohey, K. (2015). The security agencies' perspective. In M. Parent \& J. L. Chappelet (Eds.), Routledge handbook of sports event management (pp. 373-396). London, UK: Routledge.

United Nations. (2014). Sendai framework for disaster risk reduction, 2015-2030. Retrieved from https://www. unisdr.org/we/inform/publications/43291

Walters, G., Shipway, R., Miles, L., \& Aldrigui, M. (2017). Fandom and risk perceptions of Olympic tourists. Annals of Tourism Research, 66, 210-212. 
Copyright of Event Management is the property of Cognizant, LLC and its content may not be copied or emailed to multiple sites or posted to a listserv without the copyright holder's express written permission. However, users may print, download, or email articles for individual use. 